\title{
Production and characterisation of monoclonal antibodies to Brucella melitensis cytosoluble proteins that are able to differentiate antibody responses of infected sheep from Rev. 1 vaccinated sheep
}

\author{
A. CLOECKAERT, H. SALIH-ALJ DEBBARH, M. S. ZYGMUNT and G. DUBRAY
}

Laboratoire de Pathologie Infectieuse et Immunologie, Institut National de la Recherche Agronomique, 37380 Nouzilly, France

\begin{abstract}
Monoclonal antibodies (MAbs) were produced to Brucella melitensis cytosoluble proteins (CP) with apparent molecular masses of 12, 24 and $28 \mathrm{kDa}$ (CP12, CP24 and CP28) which were previously shown by immunoblotting to differentiate antibody responses of infected sheep from those of $B$. melitensis strain Rev. 1 vaccinated sheep. These MAbs were derived from mice infected with virulent smooth (S) B. melitensis strain $\mathbf{H} 38$. Most MAbs obtained were directed to CP28, which indicated (as was shown in infected sheep) that this protein was also highly immunogenic in mice. A large number of MAbs that showed reactivity to $\mathrm{CP}$ in ELISA but did not show reactivity in immunoblotting of $\mathrm{CP}$ were also obtained and might recognise conformational epitopes of these proteins. MAbs were used to localise CP12, CP24 and CP28. None of the MAbs reacted with whole $B$. melitensis cells in ELISA but showed reactivity with sonicated bacteria in ELISA, which indicated an internal localisation of these proteins. Among several B. melitensis B115 subcellular fractions tested, the anti-CP12 and anti-CP28 MAbs reacted essentially with the CP extract (CPE) in both ELISA and immunoblotting, whereas the anti-CP24 MAbs reacted with both CPE and cell envelope fraction (CEF) - although with lower intensity to the latter fraction. The internal localisation of these proteins was confirmed by immuno-electron microscopy of thin-sectioned $B$. melitensis B115 or B. melitensis 16M cells. Immunogold labelling was mainly observed in the cytoplasm and, consequently, CP12, CP24 and CP28 are probably cytoplasmic proteins. Immunoblotting of whole cell lysates with the MAbs also showed the presence of these proteins in all Brucella species and biovars, including the vaccine strains $B$. melitensis Rev. 1 and $B$. abortus B19. The use of these MAbs should help further study of antibody responses in sheep and other hosts and may be of considerable value for developing new diagnostic tests for ovine brucellosis.
\end{abstract}

\section{Introduction}

Brucellae are gram-negative facultative intracellular pathogens that may cause serious diseases in both man and animals. Brucella melitensis and B. ovis are the main Brucella species involved in ovine brucellosis. $B$. melitensis may cause abortion in sheep, which results in huge economic losses, particularly in Mediterranean countries. Laboratory diagnosis is mainly based on serological tests, i.e., Rose Bengal plate test (RBPT), seroagglutination test (SAT) and complement fixation test (CF) [1]. It is assumed that antibody responses to smooth lipopolysaccharide (S-LPS) and more precisely

Received 15 Jan. 1996; revised version accepted 15 Feb. 1996.

Corresponding author: Dr A. Cloeckaert. to the O-polysaccharide (O-PS), which is the most exposed or accessible antigen of the cell surface of smooth bacteria [2] are measured by these tests [3]. Vaccination against $B$. melitensis infection is done by inoculating sheep with the live attenuated smooth $B$. melitensis Rev. 1 strain, which also elicits a longlasting serological response against O-PS [4]. Consequently, differentiation between infected and vaccinated animals by the standard serological tests is difficult.

A previous study [5] identified a number of $B$. melitensis cytosoluble proteins (CP) by immunoblotting, mainly proteins ranging in apparent molecular masses from 10 to $32 \mathrm{kDa}$, which made distinction possible between antibody responses from $B$. melitensis Rev. 1 vaccinated sheep and those from sheep naturally and experimentally infected with $B$. meliten- 
sis. Among these CP, a 28-kDa protein (CP28) seemed to be the most interesting regarding specificity and number of infected animals detected [5].

The present study reports the immunogenicity of $\mathrm{CP}$ in mice after infection by virulent $\mathrm{S} B$. melitensis strain $\mathrm{H} 38$, vaccine strain Rev. 1, R B. melitensis strain B115 and $\mathrm{R} B$. ovis strain 63/290, and the production and characterisation of monoclonal antibodies (MAbs) to 12-, 24- and 28-kDa CP (CP12, CP24 and CP28). The use of these MAbs permitted the localisation of these $\mathrm{CP}$ in $B$. melitensis cells and fractions and the determination of their occurrence in other Brucella species and biovars.

\section{Materials and methods}

\section{Bacterial strains}

Brucella strains used were B. abortus strains 544 (biovar 1), B19 (biovar 1, vaccine strain), 86/8/59 (biovar 2), Tulya (biovar 3), 292 (biovar 4), B3196 (biovar 5), 870 (biovar 6) and C68 (biovar 9); $B$. melitensis strains 16M (biovar 1), Rev. 1 (biovar 1, vaccine strain), 63/9 (biovar 2), Ether (biovar 3) and B115 (R); B. suis strains 1330 (biovar 1), Thomsen (biovar 2), 686 (biovar 3), 40 (biovar 4) and 513 (biovar 5); B. ovis strain 63/290; B. canis strain RM6/ 66 ; $B$. neotomae strain $5 \mathrm{~K} 33$. They were from the Brucella Culture Collection, maintained at INRA, Nouzilly, France by J. M. Verger and M. Grayon. Bacterial cultures were grown on Trypticase Soy Agar (TSA) (bioMérieux, Marcy L'Etoile, France) supplemented with yeast extract (TSAYE medium) (Difco Laboratories, Detroit, MI) $0.1 \% \mathrm{w} / \mathrm{v}$. For fastidious strains (B. abortus 63/9, and B. ovis 63/290), sterile equine serum (bioMérieux) was added to TSAYE medium to a final concentration of $5 \% \mathrm{v} / \mathrm{v}$ (TSAYES medium). Strains were checked for purity, species and biovar characterisation by standard procedures [1].

\section{Antigens}

CP extract (CPE), cell envelope fraction (CEF), cellwall fraction $(\mathrm{CW})$, sodium dodecyl sulphate-insoluble (SDS-I) and -soluble (SDS-S) cell-wall fractions from B. melitensis B115 (R) and O-polysaccharide (O-PS) from $B$. melitensis $16 \mathrm{M}$ were prepared as described previously [4-11]. CP28 was partially purified from $B$. melitensis B115 CPE by preparative SDS-PAGE and excision and electro-elution of the $28-\mathrm{kDa}$ band as described previously [8]. Whole cell lysates of the different Brucella species and biovars were prepared from 24 -h slant cultures (c. $10^{10}$ bacteria) harvested in $3 \mathrm{ml}$ of sterile $\mathrm{H}_{2} \mathrm{O}$ and centrifuged at $5000 \mathrm{~g}$ for $30 \mathrm{~s}$. The pellets were lysed by heating for $10 \mathrm{~min}$ at $100^{\circ} \mathrm{C}$ in $500 \mu \mathrm{l}$ of modified Laemmli sample buffer $(62.5 \mathrm{mM}$ Tris, SDS 2\%, $100 \mathrm{mM}$ DTT, glycerol 10\%, pH 6.8) and dissolved proteins were further analysed by SDSPAGE and immunoblotting.

\section{Mice, immunisations and hybridomas}

Groups of five 8 -week-old female BALB/c mice were inoculated intraperitoneally with $10^{7} \mathrm{cfu}$ of $B$. melitensis strain H38, B. melitensis strain Rev. 1, $B$. melitensis strain B115 (R), or B. ovis strain 63/290 (R). Mice were bled 5 weeks later to evaluate antibody responses to $\mathrm{CPE}$ and $\mathrm{CEF}$ antigens. Three months after challenge mice infected with $B$. melitensis strain $\mathrm{H} 38$ were boosted intravenously with $30 \mu \mathrm{g}$ of partially purified CP28 and on the following day intraperitoneally with $300 \mu \mathrm{g}$ of CPE and intravenously with $40 \mu \mathrm{g}$ of CP28. Two days after the last booster injection, spleen cells were fused with cells of the X63 nonsecreting myeloma cell line at a ratio of 5:1. After fusion, cells were suspended in selective hypoxanthineaminopterin-thymidine-containing medium and seeded in 96-well microtitration plates at $10^{5}$ splenocytes/well. Anti-Brucella hybridomas (tissue culture supernates diluted 1 in 3) were screened by ELISA with CPE, CEF and $\mathrm{CP} 28$ as antigens. Hybridomas of interest were cloned by the limiting-dilution technique.

\section{ELISA}

ELISA on CP28, CPE, CEF, CW, SDS-I, SDS-S and OPS antigens and on $B$. melitensis $\mathrm{B} 115$ whole or sonicated bacteria was performed as described previously [2,9]. Antigens were coated overnight at room temperature on microtitration plates at a concentration of $20 \mu \mathrm{g} / \mathrm{ml}$ in phosphate-buffered saline (PBS) for all antigen preparations except for O-PS which was at a concentration of $3 \mu \mathrm{g} / \mathrm{ml}$. B. melitensis B1 15 bacterial cells were coated on microtitration plates suspended at an absorbance $(600 \mathrm{~nm})$ value of 1.0. Binding of mouse polyclonal antibodies (sera serially diluted in PBS containing Tween $200.05 \%$; PBS-T) or MAbs (hybridoma supernates diluted 1 in 3 or serially diluted in PBS-T) was detected by peroxidase-conjugated goat anti-mouse immunoglobulins (BioRad, France) diluted 1 in 3000 in PBS-T. Substrate solution for detecting peroxidase activity was $4 \mathrm{mM} \mathrm{H}_{2} \mathrm{O}_{2}$ and $1 \mathrm{mM}$ ABTS 2,2-azino-di-(3-ethylbenzthiazoline-sulphonic acid) in $50 \mathrm{~mm}$ sodium citrate, $\mathrm{pH}$ 4.2. Absorbance values at $414 \mathrm{~nm}$ were recorded with an automatic ELISA reader (Bio-Tek EL 312, Packard Instruments, Rungis, France).

\section{SDS-PAGE and immunoblotting techniques}

SDS-PAGE and immunoblotting of CPE, CEF (deposits of $60 \mu \mathrm{g}$ ), or whole cell lysates (deposits of $20 \mu \mathrm{l}$ ) were performed as described previously $[4,5]$. Binding of mouse polyclonal antibodies (sera diluted 1 in 100) or MAbs ( 1 in 3 or serially diluted hybridoma supernates) was detected by rabbit anti-mouse immunoglobulin antiserum (diluted 1 in 500) (Nordic Immunology, Tilburg, The Netherlands) and peroxidase-conjugated protein A (diluted 1 in 1000) (Sigma). Binding of sheep polyclonal antibodies (sera diluted 1 in 100) was 
detected by peroxidase-conjugated rabbit anti-sheep IgG immunoglobulins (Jackson Immunoresearch Labs, West Grove, PA, USA). Peroxidase activity was revealed with the development kit from BioRad S.A., Paris, France, containing 4-chloro-1-naphtol, according to the manufacturer's instructions.

\section{Immuno-electron microscopy}

Thin sections of B. melitensis B115 or B. melitensis $16 \mathrm{M}$ whole bacteria were prepared as described previously [6] except that samples were embedded in LR White resin. Immunogold labelling was performed as described previously $[2,6]$ but without pretreatment of the grids in $\mathrm{H}_{2} \mathrm{O}_{2}$ solution. Binding of MAbs (hybridoma supernates diluted 1 in 3 in PBS-T) was detected with sheep anti-mouse biotinylated immunoglobulins (diluted 1 in 200 in PBS-T) (Amersham) and gold-labelled streptavidin (diluted 1 in 20 in PBS-T; $15 \mathrm{~nm}$ ) (Amersham).

\section{$M A b$ isotypes}

$\mathrm{MAb}$ isotypes were determined by the Isotype AbSTAT-I system (Sangstat Medical Corporation, Menio Park, CA, USA).

\section{Results}

Antibody responses to $C P$ in mice after infection

Antibody responses in BALB/c mice to $\mathrm{CP}$ induced by infection by $B$. melitensis strains $\mathrm{H} 38$ (S), Rev. 1 (S), $\mathrm{B} 115(\mathrm{R})$ and $B$. ovis strain $63 / 290$ were first measured by ELISA, 5 weeks after challenge, with CPE and CP28 as coating antigens (Fig. 1). The highest antibody titres to CPE were observed in the mice infected with $\mathrm{S}$ B. melitensis strains $\mathrm{H} 38$ and Rev. 1 (Fig. 1a). The antibody titres were 50-100 times lower in the mice infected with R B. melitensis B115 and B. ovis 63/290. The antibody responses to CP28 were also the highest in mice infected with $B$. melitensis $\mathrm{H} 38$ and decreased respectively in mice infected with $B$. melitensis Rev. 1 and B115 and B. ovis 63/290 (Fig. 1b). Mice infected with the two latter strains showed similar antibody titres which were 200 times lower than in mice infected with B. melitensis $\mathrm{H} 38$.

The higher antibody responses to $\mathrm{CP}$ induced by infection with $\mathrm{S} B$. melitensis strains (H38 and Rev. 1) were confirmed by immunoblotting of CPE (Fig. 2). A large number of protein bands ranging in apparent molecular mass from 12 to $100 \mathrm{kDa}$, of which proteins previously identified as discriminating antibody responses of $B$. melitensis infected from Rev. 1 vaccinated sheep [5], were recognised by sera of mice infected with both $\mathrm{H} 38$ and Rev. 1. The antibody responses to $\mathrm{CP}$ in mice infected with $B$. melitensis B115 and B. ovis 63/290 were much lower according to the staining intensity of the protein bands.
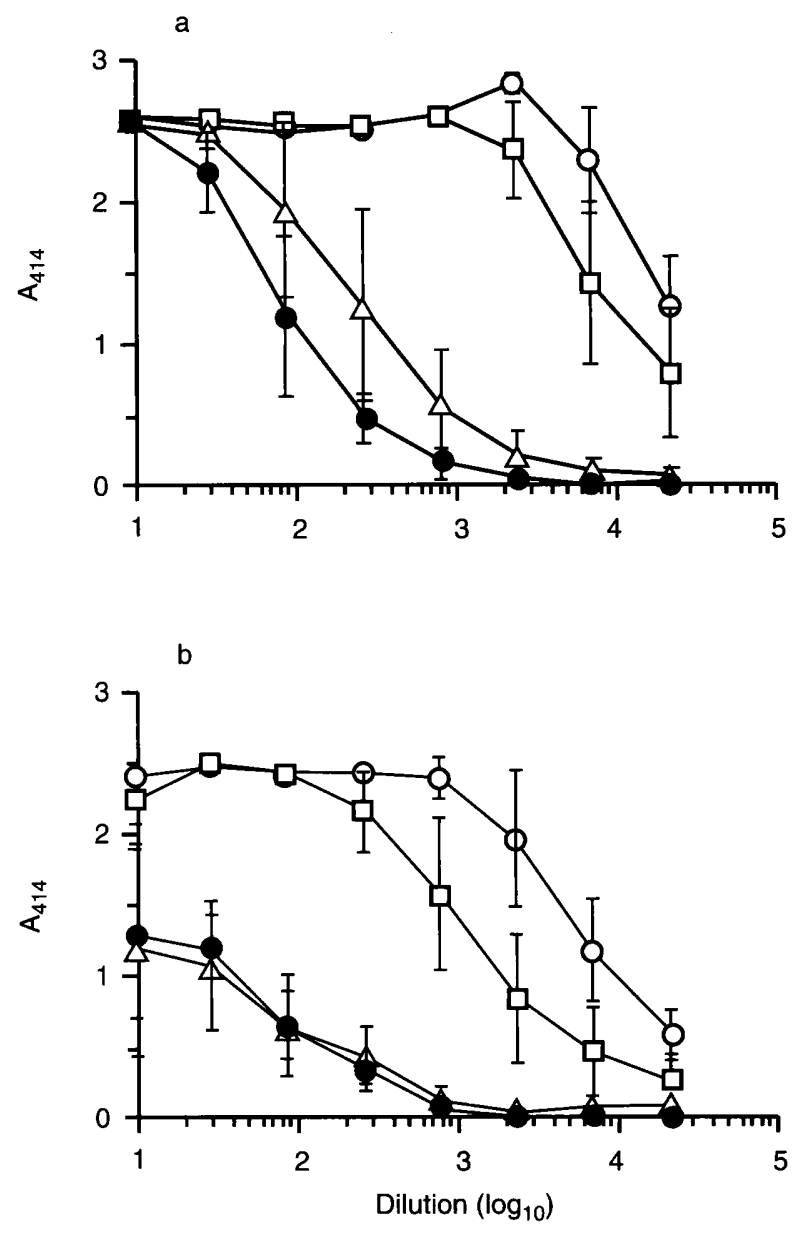

Fig. 1. Antibody reactivity measured by ELISA to $B$. melitensis $\mathrm{B} 115 \mathrm{CPE}$ (a) and $\mathrm{CP} 28$ (b) antigens of sera from $\mathrm{BALB} / \mathrm{c}$ mice (mean absorbance and SD of five mice) infected with $B$. melitensis strains H38 (S) (O), Rev. 1 (S) $(\square)$ or B115 (R) $(\triangle)$ or B. ovis strain $63 / 290$ (R) (O) (5 weeks after challenge).

As antibody responses to $\mathrm{CP}$ were the highest in mice infected with $B$. melitensis $\mathrm{H} 38$, these mice were further used for MAb production.

\section{$M A b s$}

Tissue culture supernates from hybridomas were screened initially for the presence of antibody by ELISA with CPE, CEF and CP28 as coating antigens. Reactivity to O-PS was also further monitored by ELISA. MAb specificity of ELISA positive hybridoma supernates was thereafter determined by immunoblotting with CPE or CEF (Fig. 3) as antigens. Most hybridomas produced antibodies to CP28 (Table 1). The other protein specificities were CP12, CP24 and a $73-\mathrm{kDa}$ protein. MAbs to the latter protein bound only to CEF in ELISA and immunoblotting and were further shown to be specific for the heat shock protein (HSP) DnaK by their reactivity with the $B$. melitensis DnaK protein produced in Escherichia coli [12]. MAbs to CP28 showed high reactivity in ELISA on CPE (most absorbance values were $>1.5$ ) and reacted poorly with 


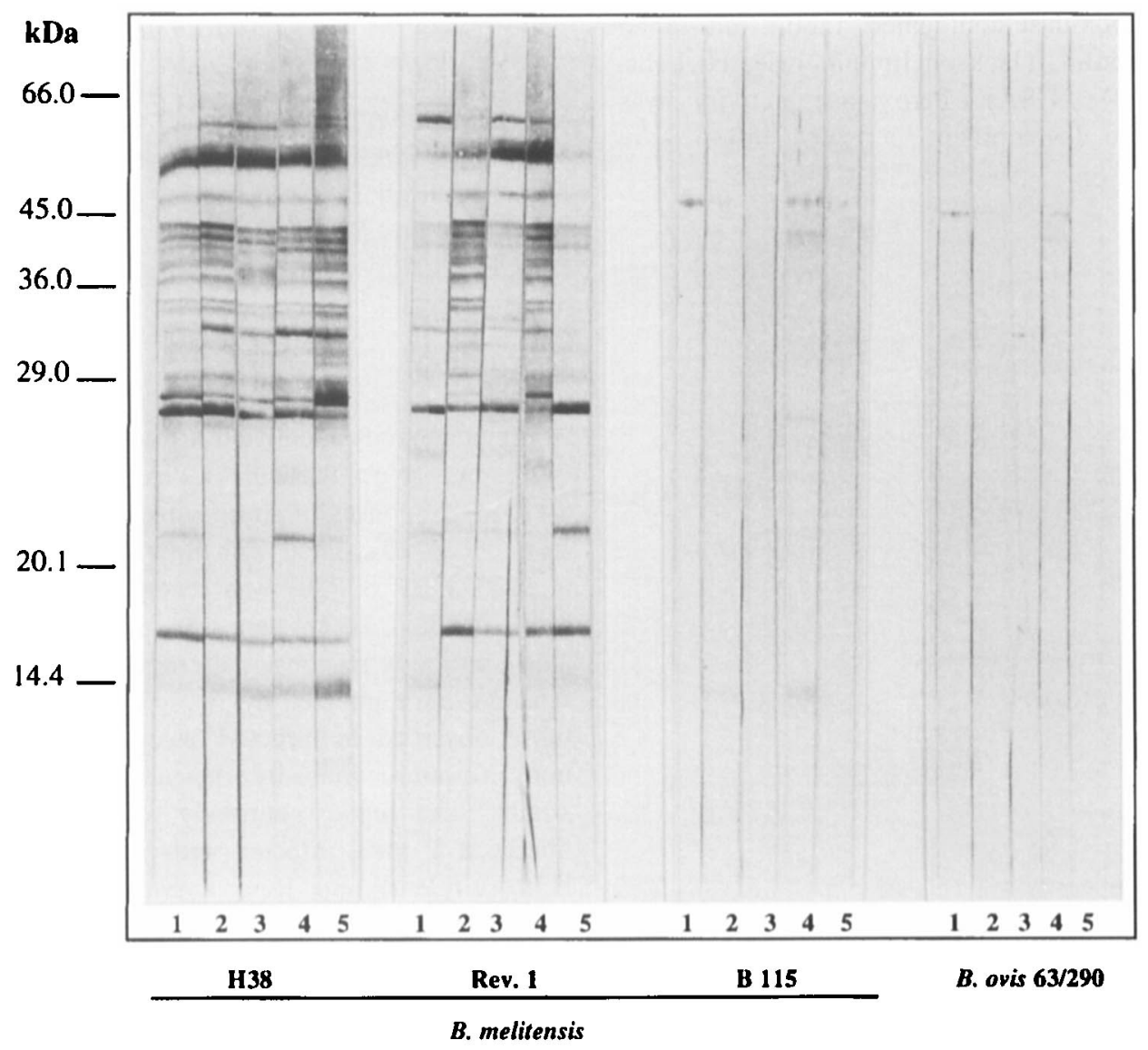

Fig. 2. Antibody responses detected by immunoblotting of B. melitensis B115 CPE antigens with sera (diluted 1 in 100) from BALB/c mice (five mice sera for each challenge) infected with B. melitensis strains H38 (S), Rev. 1 (S) or B115 (R) or B. ovis strain $63 / 290(\mathrm{R})$ (5 weeks after challenge).

CEF (absorbance values $<0.5$ ) (Table 1 ). The MAb specific for CP12 also showed better antibody reactivity to $\mathrm{CPE}$ (absorbance value of 0.8 ). MAbs to CP24 reacted with both CPE and CEF in ELISA but preferentially with CPE (absorbance values around 2.0 and 1.2 respectively). Only MAbs to CP28 bound to partially purified CP28 in ELISA (absorbance values $>2.0$ ). ELISA results were confirmed by immunoblotting, i.e., the anti-CP24 MAbs showed high antibody reactivity on both CPE and CEF while MAbs specific for $\mathrm{CP} 12$ and $\mathrm{CP} 28$ reacted only with CPE (Fig. 3).

Twenty-one hybridomas were also obtained with supernates showing antibody reactivity in ELISA either on CPE or CEF (half of these reacted better with $\mathrm{CPE}$ ) but which did not show antibody reactivity in immunoblotting.

In addition, three hybridomas were shown by ELISA to secrete antibodies specific for O-PS epitopes.

MAbs to CP12, CP24 and CP28 reacted in immunoblotting to protein bands of CPE also recognised by serum antibodies of sheep infected naturally with $B$. melitensis and infected experimentally with strain H38 (Fig. 4)
Localisation of CP12, CP24 and CP28 in B. melitensis cells and fractions

Reactivity of MAbs with B. melitensis cells and subcellular fractions. MAbs to CP12, CP24 and CP28 were further used to determine localisation and presence of these proteins in other subcellular fractions, i.e., CW, SDS-I and SDS-S fractions of B. melitensis $\mathrm{B} 1$ 15. $\mathrm{CPE}$ and $\mathrm{CEF}$ were added for comparison. None of the MAbs bound to whole B. melitensis B115 bacteria in ELISA, but bound to sonicated bacteria indicating an exclusively intracellular localisation of these CP (Fig. 5). MAbs to CP12 and CP28 bound only to $\mathrm{CPE}$ and in a limited manner to CEF. Only the MAbs specific for CP24 bound weakly (absorbance value of 0.6 ) to $\mathrm{CW}$ fraction. The latter MAbs also bound to SDS-S fraction (absorbance value of 1.9) but did not bind to SDS-I fraction.

Localisation by immuno-electron microscopy. The internal localisation of $\mathrm{CP} 12, \mathrm{CP} 24$ and $\mathrm{CP} 28$ was confirmed by immuno-electron microscopy of thin sections of $B$. melitensis $\mathrm{B} 115$ or $16 \mathrm{M}$ cells (not shown). The immunogold labelling observed was mainly cytoplasmic. 


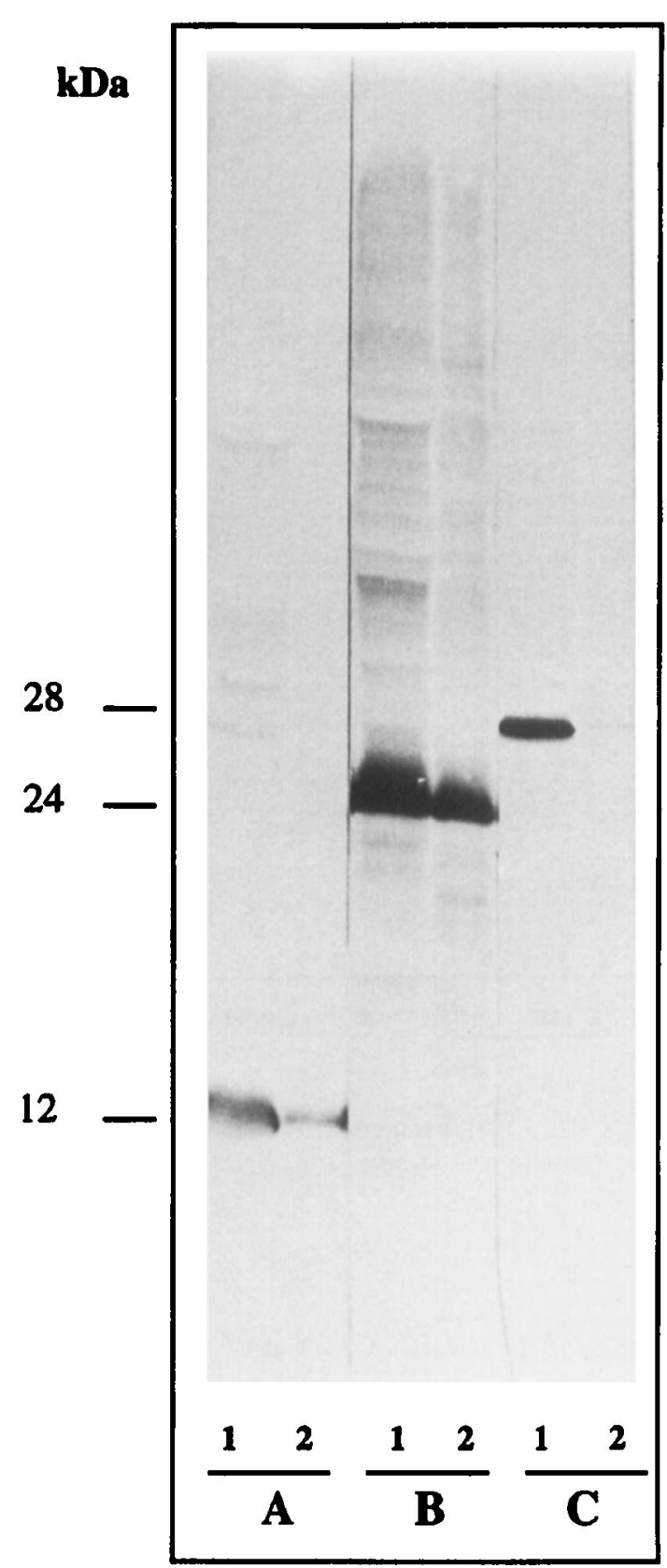

Fig. 3. MAb reactivity in immunoblotting of $B$. melitensis B115 CPE (lane 1) and CEF (2). A, reactivities of antiCP12 MAb V78/01B10/G05 (IgG2a); B, reactivities of anti-CP24 MAb V78/04C12/A12 (IgG2a); C, reactivities of anti-CP28 MAb V78/05G03/H03 (IgG2a).

Table 1. Brucella-specific hybridomas

\begin{tabular}{lcccc}
\hline & \multirow{4}{*}{$\begin{array}{c}\text { Number } \\
\text { obtained }\end{array}$} & CPE & CEF & CP28 \\
\cline { 3 - 5 } Specificity & 1 & ++ & + & - \\
\hline $12 \mathrm{kDa}$ & 3 & +++ & +++ & - \\
$24 \mathrm{kDa}$ & 23 & +++ & + & +++ \\
$28 \mathrm{kDa}$ & 3 & - & +++ & - \\
$73 \mathrm{kDa}^{*}$ & 3 & - & +++ & - \\
O-PS & $21^{\dagger}$ & & & \\
Unknown & & & & \\
\hline
\end{tabular}

${ }^{*}$ MAbs to the 73-kDa protein were further shown to be specific for the heat shock protein DnaK.

${ }^{\dagger}$ Eleven MAbs with unknown specificity reacted preferentially with CPE in ELISA, the others reacted preferentially with CEF.

\section{Occurrence of CP12, CP24 and CP28 in} Brucella species and biovars

By immunoblotting of whole cell lysates with the MAbs, the presence of $\mathrm{CP} 12, \mathrm{CP} 24$ and $\mathrm{CP} 28$ was observed in all Brucella species and biovars, including vaccine strains $B$. melitensis Rev. 1 and B. abortus B19 (Fig. 6).

\section{Discussion}

A previous study identified a number of protein bands by immunoblotting with CPE which discriminated antibody responses of sheep infected with B. melitensis from sheep vaccinated with Rev. 1 [5]. Among the CP, a $28-\mathrm{kDa}$ CP (CP28) was recognised by antibody of most infected sheep sera. As shown in the present study, antibody response patterns to $B$. melitensis $\mathrm{CP}$ in $\mathrm{BALB} / \mathrm{c}$ mice infected by $B$. melitensis were similar to those observed in infected sheep. However, the antibody response intensity depended on the challenge strains. The highest antibody responses to $\mathrm{CP}$ were observed in mice infected with $\mathrm{S} B$. melitensis strains H38 (virulent) and Rev. 1 (vaccine). The antibody responses in $\mathrm{BALB} / \mathrm{c}$ mice infected by $\mathrm{R} B$. melitensis strain B115 and B. ovis strain 63/290 were appreciably lower. These observations are probably related to the pathogenicity and persistence of the strains used. S Brucella strains are considered to be more virulent than $\mathrm{R}$ strains and persist for longer in the host [13-18]. Therefore, to produce MAbs of interest, spleen cells from mice infected with $B$. melitensis strain $\mathrm{H} 38$ were chosen for hybridoma production. In addition, these mice were boosted with CPE and CP28 enriched fraction. The fact that only a limited number of hybridomas was obtained with O-PS specificity may be due to the absence or limited content of O-PS in the antigen preparations used for booster injections performed before the fusion experiment. The high immunogenicity of CP28 was reflected by the great number of CP28-specific hybridomas obtained. The other hybridomas obtained that secreted MAbs specific for $\mathrm{CP} 12$ and $\mathrm{CP} 24$ are also of interest, as CP12 and CP24 were also shown to be specific to infection status in sheep although antibody responses to these $\mathrm{CP}$ were more heterogeneous than antibody responses to CP28 [5].

An interest in anti-protein MAb production by infection of mice has been shown previously by us [2] and more recently by others [19]. This includes the possibility of obtaining MAbs specific for native protein epitopes recognised during infection in different hosts $[2,9,20]$. Such MAbs were obtained and were directed to the major Brucella outer-membrane proteins (OMPs) of $25-27$ and $36-38 \mathrm{kDa}[2,20]$. In the present study, a number of hybridomas secreted MAbs that showed high reactivity to CPE in ELISA but did not react in immunoblotting after SDS-PAGE of $\mathrm{CPE}$, and that, therefore, probably recognise 


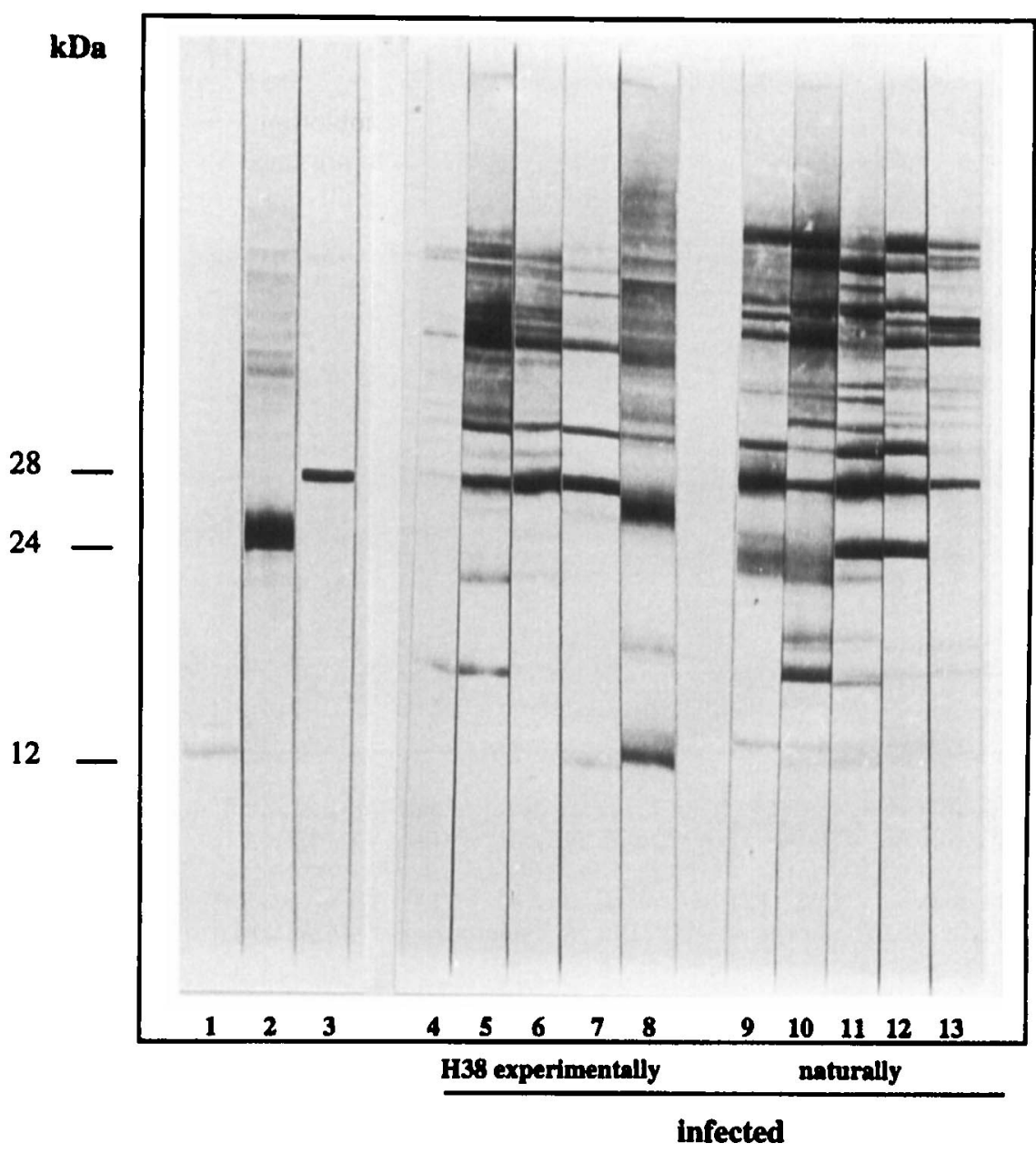

Fig. 4. Immunoblotting of $B$. melitensis $\mathrm{B} 115 \mathrm{CPE}$ with: lane 1, anti-CP12 MAb V78/01B10/G05; 2, anti CP24 MAb $\mathrm{V} 78 / 04 \mathrm{C} 12 / \mathrm{A} 12 ; 3$, anti-CP28 MAb V78/05G03/H03; 4-8, sera from sheep experimentally infected with $B$. melitensis strain H38 (S); 9-13, sera from sheep naturally infected with $B$. melitensis.

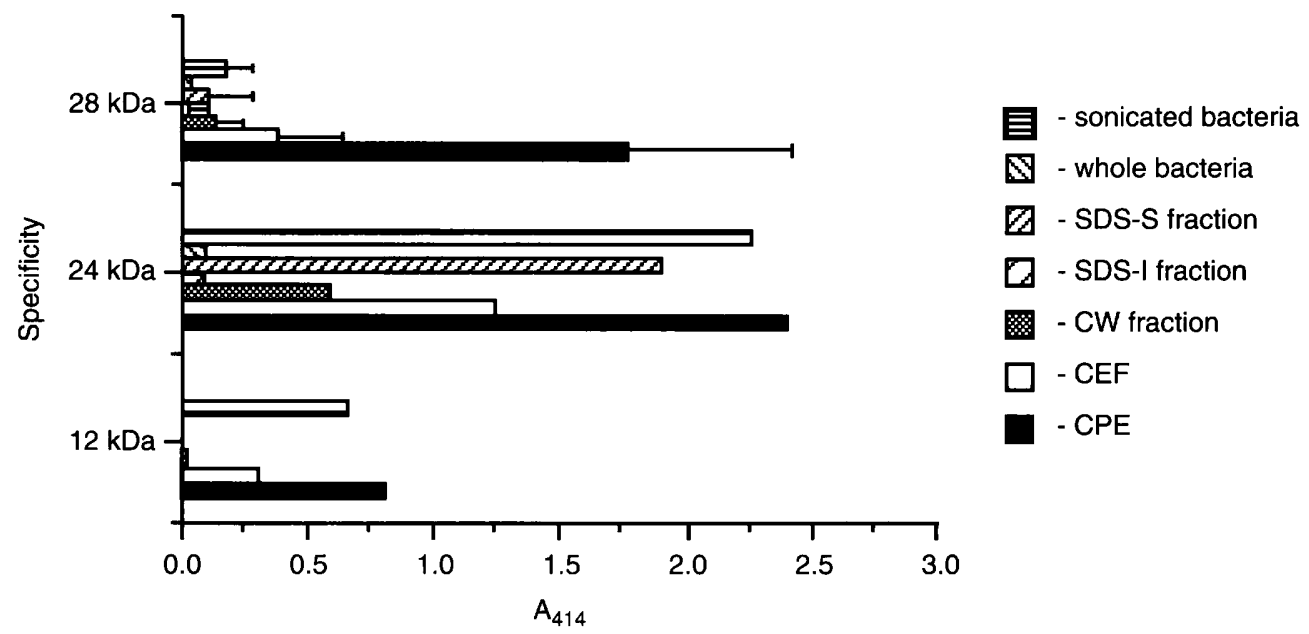

Fig. 5. ELISA binding of anti-CP28 MAbs (mean absorbance and SD of 23 MAbs), anti-CP24 MAb V78/04C12/A12 and anti-CP12 MAb V78/01B10/G05 (three-fold diluted hybridoma supernates) to $B$. melitensis B115 cells and subcellular fractions.

conformational CP epitopes. The specificities of these MAbs should be determined under non-denaturing conditions. Furthermore, the production of such MAbs shows that during infection a number of immunogenic
CP epitopes that cannot be resolved by such methods as SDS-PAGE and immunoblotting may also be relevant for diagnostic purposes. As alternatives to the latter technique to identify such CP epitopes, 


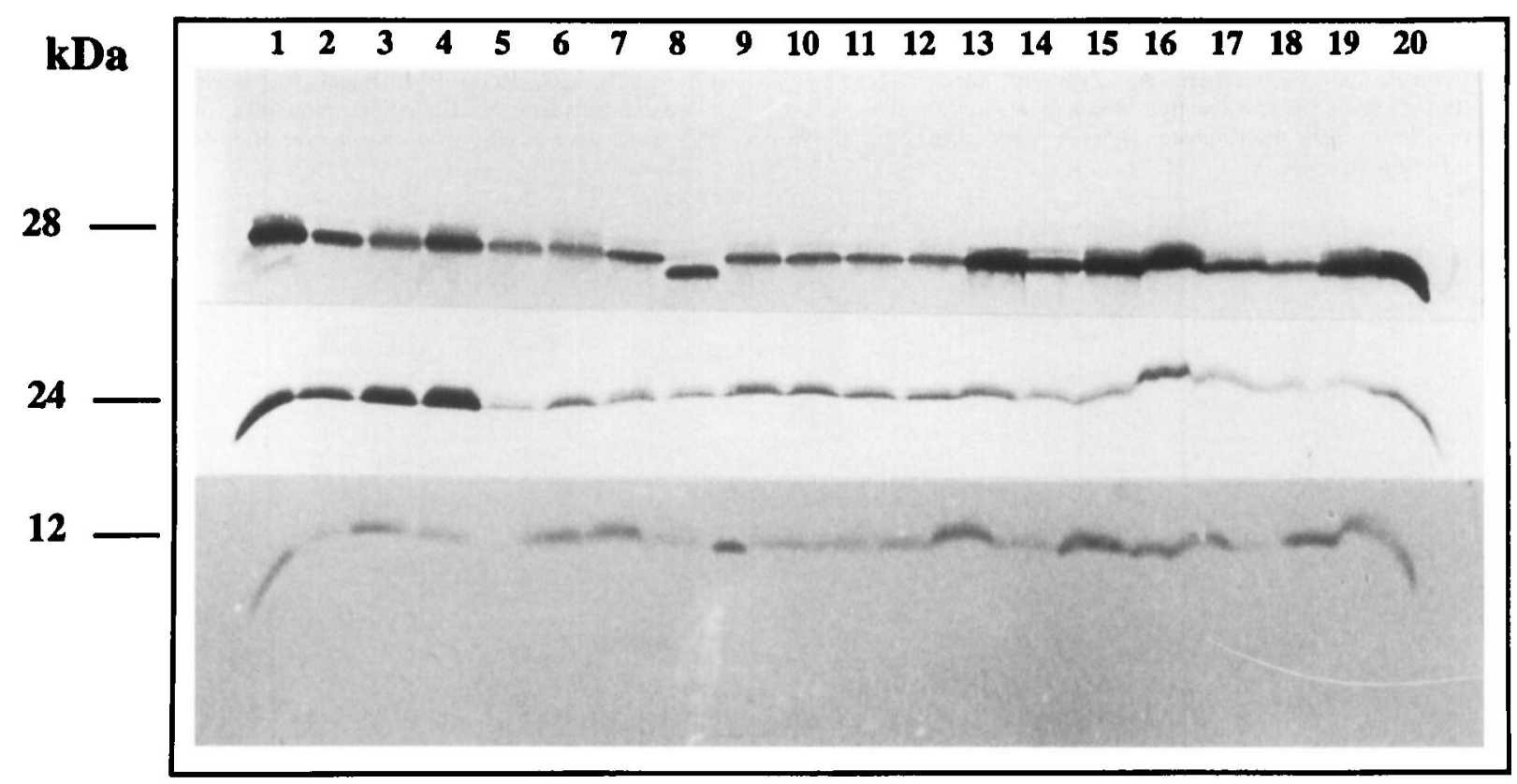

Fig. 6. Occurrence of $\mathrm{CP} 12, \mathrm{CP} 24$, and $\mathrm{CP} 28$ in Brucella species and biovars. Immunoblotting with anti-CP12 MAb V78/01B10/G05, anti-CP24 MAb V78/04C12/A12, and anti-CP28 MAb V78/05G03/H03 of whole-cell lysates from $B$. melitensis strains 16M (lane 1), Rev. 1 (2), 63/9 (3), Ether (4); B. abortus strains 544 (5), B19 (6), 86/8/59 (7), Tulya (8), 292 (9), B3196 (10), 870 (11), C68 (12); B. suis strains 1330 (13), Thomsen (14), 686 (15), 40 (16), 513 (17); B. neotomae strain $5 \mathrm{~K} 33(\mathbf{1 8}) ;$ B. ovis strain $63 / 290(\mathbf{1 9}) ;$ B. canis strain RM6/66 (20).

isoelectric focusing, as previously reported [11], or PAGE under non-denaturing conditions [21] should be more appropriate.

Localisation of CP12, CP24 and CP28, as shown by immuno-electron microscopy, seemed to be essentially cytoplasmic. However, the anti-CP24 MAbs showed high reactivity in ELISA and immunoblotting both with CPE and CEF. These MAbs also showed high reactivity in ELISA to SDS-S and less intensely to $\mathrm{CW}$ fractions. Interaction of $\mathrm{CP} 24$ with some insoluble membrane proteins could be the cause of non-specific location of this CP in the different subcellular fractions tested. A similar observation was made with the MAbs specific for the $B$. melitensis DnaK protein. By use of immuno-electron microscopy with the anti-DnaK MAbs, immunogold labelling was essentially restricted to the cytoplasm, although these MAbs did not bind to CPE and showed high reactivity to $\mathrm{CEF}$ [12].

One of the major objectives in the field of brucellosis is the identification of protein antigens as diagnostic antigens as alternatives to O-PS to improve specificity and the possibility of differentiating infected from vaccinated animals. Reported studies have focused on cytosoluble and membrane proteins $[4,5,8-11,19$, 20, 22-26]. Ideally, a new diagnostic test should be based on a single specific protein allowing detection of Brucella infection in different hosts. Whereas antibody responses to OMPs were low or heterogeneous in sheep infected with $B$. melitensis $[4,9]$ or in cattle infected with $B$. abortus $[8,20,25]$, the present study identified CP28, which was recognised by serum from most sheep infected with B. melitensis [5] and therefore seemed to be more appropriate than OMPs in the development of such a diagnostic test. As shown in the present study, this CP is expressed in all Brucella species and biovars. This was not the case, for example, for BCSP31, a periplasmic protein of interest in bovine brucellosis, which was shown to occur in all Brucella species except B. ovis [23]. The potential usefulness of CP28 as a diagnostic antigen should therefore be tested in infections caused by other Brucella species, including sheep infected with $B$. ovis. As this protein is also present in vaccine strains B. melitensis Rev. 1 and B. abortus B19, gene deletion mutants should be constructed to ensure differential diagnosis of Brucella infection versus vaccination, as was done for BCSP31 [27, 28].

We are grateful to J.-M. Verger and M. Grayon for supplying strains We thank G. Bézard and J.-C. Nicolle for expert technical assistance. A. C. was supported by a CEC fellowship.

\section{References}

1. Alton GG. Techniques for the brucellosis laboratory. Institut National de la Recherche Agronomique, Paris. 1988.

2. Cloeckaert A, de Wergifosse P, Dubray G, Limet JN. Identification of seven surface-exposed Brucella outer membrane proteins by use of monoclonal antibodies: immunogold labeling for electron microscopy and enzyme-linked immunosorbent assay. Infect Immun 1990; 58: 3980-3987.

3. Dubray G. Antigens of diagnosis significance in Brucella. In: Verger JM, Plommet M (eds) Brucella melitensis C.E.C. Seminar. Dordrecht, Martinus Nijhoff Publishers. 1985: 123138.

4. Zygmunt MS, Debbarh HS, Cloeckaert A, Dubray G. Antibody response to Brucella melitensis outer membrane antigens in 
naturally infected and Revl vaccinated sheep. Vet Microbiol 1994; 39: 33-46.

5. Debbarh HS, Cloeckaert A, Zygmunt MS, Dubray G. Identification of sero-reactive Brucella melitensis cytosoluble proteins which discriminate between antibodies elicited by infection and Rev. 1 vaccination in sheep. Vet Microbiol 1995; 44: $37-48$.

6. Cloeckaert A, Zygmunt MS, Nicolle J-C, Dubray G, Limet JN. O-chain expression in the rough Brucella melitensis strain B115: induction of O-polysaccharide-specific monoclonal antibodies and intracellular localization demonstrated by immunoelectron microscopy. J Gen Microbiol 1992; 138: 12111219.

7. Dubray G, Charriaut C. Evidence of three major polypeptide species and two major polysaccharide species in the Brucella outer membrane. Ann Rech Vet 1983; 14: 311-318.

8. Limet JN, Cloeckaert A, Bezard G, Van Broeck J, Dubray G. Antibody response to the $89-\mathrm{kDa}$ outer membrane protein of Brucella in bovine brucellosis. J Med Microbiol 1993; 39: 403-407.

9. Zygmunt MS, Cloeckaert A, Dubray G. Brucella melitensis cell envelope protein and lipopolysaccharide epitopes involved in humoral immune responses of naturally and experimentally infected sheet. $J$ Clin Microbiol 1994; 32: 2514-2522.

10. Zygmunt MS, Gilbert FB, Dubray G. Purification, characterization, and seroactivity of a 20-kilodalton Brucella protein antigen. J Clin Microbiol 1992; 30: 2662-2667.

11. Zygmunt MS, Martin J-C, Dubray G. Analysis of immune response: comparison of immunoblots after isoelectric focusing and sodium dodecyl sulfate-polyacrylamide gel electrophoresis using cytoplasmic protein extract from Brucella. FEMS Microbiol Lett 1990; 70: 263-268.

12. Cloeckaert A, Grepinet O, Salih-Alj Debbarh H, Zygmunt MS 1996. Overproduction of the Brucella melitensis heat shock protein DnaK in Escherichia coli and its localization by use of specific monoclonal antibodies in $B$. melitensis cells and fractions. Res Microbiol 1996; 147: 145-147.

13. Alton GG. The occurrence of dissociated strains of Brucella melitensis in the milk of goats in Malta. J Comp Pathol 1960; 70: $10-17$

14. Harmon BG, Adams LG, Frey M. Survival of rough and smooth strains of Brucella abortus in bovine mammary gland macrophages. Am J Vet Res 1988; 49: 1092-1097.

15. Jones LM, Diaz R, Taylor AG. Characterization of allergens prepared from smooth and rough strains of Brucella melitensis. Br J Exp Pathol 1973; 54: 492-508.

16. Kreutzer DL, Robertson DC. Surface macromolecules and virulence in intracellular parasitism: comparison of cell envelope components of smooth and rough strains of Brucella abortus. Infect Immun 1979; 23: 819-828.

17. Schurig GG, Roop RM, Bagchi T, Boyle S, Buhrman D, Sriranganathan N. Biological properties of RB51; a stable rough strain of Brucella abortus. Vet Microbiol 1991; 28: 171188.

18. Tobias L, Schurig GG, Cordes DO. Comparative behaviour of Brucella abortus strains 19 and RB51 in the pregnant mouse. Res Vet Sci 1992; 53: 179-183.

19. Goldbaum FA, Leoni J, Wallach JC, Fossati CA. Characterization of an 18-kilodalton Brucella cytoplasmic protein which appears to be a serological marker of active infection of both human and bovine brucellosis. $J$ Clin Microbiol 1993; 31: 2141-2145

20. Cloeckaert A, Kerkhofs P, Limet JN. Antibody response to Brucella outer membrane proteins in bovine brucellosis: immunoblot analysis and competitive enzyme-linked immunosorbent assay using monoclonal antibodies. $J$ Clin Microbiol 1992; 30: 3168-3174.

21. Retamal C, Babul J. Determination of the molecular weight of proteins by electrophoresis in slab gels with a transverse pore gradient of crosslinked polyacrylamide in the absence of denaturing agents. Anal Biochem 1988; 175: 544-547.

22. Belzer CA, Tabatabai LB, Deyoe BL. Differentiation by western blotting of immune responses of cattle vaccinated with Brucella abortus strain 19 or infected experimentally or naturally with virulent Brucella abortus. Vet Microbiol 1991; 27: 79-90.

23. Bricker BJ, Tabatabai LB, Deyoe BL, Mayfield JE. Conservation of antigenicity in a $31-\mathrm{kDa}$ Brucella protein. Vet Microbiol 1988; 18: 313-325.

24. Chin JC, Pang-Turner B. Profiles of serological reactivity against cytosoluble antigens of Brucella ovis in experimentally infected rams. J Clin Microbiol 1990; 28: 2647-2652.

25. Gómez-Miguel MJ, Moriyón I, Alonso-Urmenata B, Riezu-Boj JI, Díaz R. Serological response to the outer membrane lipoprotein in animal brucellosis. Infect Immun 1988; 56: 716 718.

26. Riezu-Boj JI, Moriyón I, Blasco JM, Gamazo C, Díaz R. Antibody response to Brucella ovis outer membrane proteins in ovine brucellosis. Infect Immun 1990; 58: 489-494.

27. Cheville NF, Stevens MG, Jensen AE, Tatum FM, Halling SM. Immune responses and protection against infection and abortion in cattle experimentally vaccinated with mutant strains of Brucella abortus. Am J Vet Res 1993; 54: 1591-1597.

28. Halling SM, Detilleux PG, Tatum FM, Judge BA, Mayfield JE. Deletion of the BCSP31 gene of Brucella abortus by replacement. Infect Immun 1991; 59: 3863-3868. 